\title{
La herética de Martín Adán
}

\author{
Andrés PIÑEIRO / Universidad Científica del Sur
}

\section{Resumen}

Los estudiosos de la obra poética de Martín Adán han puesto el acento en lo que ésta tiene de cristiana. Así, la angustia ante la muerte aparece como un sentimiento que agobia los versos del poeta. Sin embargo, en nuestro concepto, desde el Escrito a ciegas empieza a operarse una mirada que lo distancia de la tradición cristiana, que incluso se exacerbará en los poemarios que vendrían.

\section{Palabras clave:}

Martín Adán, herejía, poesía peruana, tradición judeo cristiana.

\section{Abstract}

Most critics have stressed the importance of Christian tradition in Martin Adan's poetry. Thus, the anguish in spite of death appears as an emotion that burden the poet's verses. Instead, we think that since Escrito a ciegas there's a new point of view that takes some distance from the Christian tradition, the same that will exacerbate in his following poetry books.

\section{Key words:}

Martin Adán, heresy, Peruvian poetry, Judeo-Christian tradition. 


\section{La herética de Martín Adán}

Algunos autores se han detenido en la herejía de Martín Adán a propósito de sus textos. José Carlos Mariátegui en el colofón a La casa de cartón (1928) ha visto en la herejía del poeta un signo de la decadencia de una época signada por el civilismo en nuestro medio:

Más aún, por humorismo, Martín Adán se dice reaccionario, clerical y civilista. Pero su herejía evidente, su escepticismo contumaz, lo contradicen. El reaccionario es siempre apasionado. El escepticismo es ahora demo-burgués, como fue aristocrático, cuando la burguesía era creyente y la aristocracia enciclopedista y volteriana. Si el civilismo no es ya capaz sino de herejía, quiere decir que no es capaz de reacción. Y yo creo que la herejía de Martín Adán tiene este alcance; y por eso, me he apresurado a registrarla como signo.'

Las circunstancias históricas deciden la literatura de Martín Adán. Ésta no habría sido posible "antes del "experimento billinghurista, de la insurrección 'colónida', de la decadencia del civilismo, de la revolución del 4 de julio y de las obras de la Foundation". Estas circunstancias permitieron al poeta escribir desenfadadamente sobre temas "antiguamente respetables", referidos algunos a la tradición cristiana.

El filósofo Luis Felipe Alarco estima que las características que apreciamos en la vivencia religiosa de Adán podemos verlas también en el propio poeta y en su lenguaje. En efecto, dichas características nos ayudan a establecer una íntima relación entre las contradicciones que operan en Martín Adán en diversos planos. Más adelante hablaremos de la búsqueda racional del poeta de una realidad inefable. Nos dice Alarco:

La vivencia religiosa de Rafael (de la Fuente Benavides, Martín Adán) es múltiple y contradictoria, como él mismo. Así como se ve precisado a forcejear con el idioma, a descomponerlo y recomponerlo, asimismo su actitud existencial es ensayo, derrumbe, alzamiento, cabriola, paradoja. También su vivencia religiosa recorre todos estos parajes, mientras continúa buscando. A veces una simple oquedad en el horizonte: no es Dios quien ha creado al hombre, sino el hombre a Dios, como asevera el ateísmo. El náufrago permanece solo, sin Dios y con su nada. Empero, siente la necesidad de creer, porque si no cree, no vive; que Dios exista. De pronto retrocede irónico, sonríe, mano desasida, y sitúa su creencia al nivel del boy scout y de la máquina fotográfica ${ }^{2}$

'Mariátegui, José Carlos, Colofón a La casa de cartón de Martín Adán, Lima: Peisa, 1974, pp. 89-90.

${ }^{2}$ Alarco, Luis Felipe, Tres autores, Lima: Empresa Editora Amauta, 1995, p. 118. 
No traicionamos el pensamiento de Alarco si cambiamos el término "ateísmo" por el de "agnosticismo". Obsérvese cómo las "contradicciones" de Adán lo sitúan en una perspectiva que lo aleja de la del devoto y lo acerca a la del hereje. La presencia de la divinidad es requerida ya no por medio de la oración, sino por efecto de la blasfemia.

El poeta cree saber: Dios no acudirá a su súplica y a su herejía; volteará el rostro airado. Por eso blasfema, para que retorne con su castigo, mas también con su presencia. Es la paradoja del fango. Que hable Dios, que cese su silencio, que se manifieste con su luz o su fuego; he ahí el ansia del náufrago, más allá de su decir o de su castigo. ${ }^{3}$

Finalmente, Mirko Lauer nos habla del cambio operado en la obra poética de Martín Adán a partir de la década del sesenta. Ha quedado atrás "la corrección del estilista del soneto" en Travesía de extramares y ahora se erige el coloquialismo que tiene en La mano desasida su punto más alto de sensibilidad:

Pero algo fundamental cambió en Martín Adán durante los años 60. Un crítico literario diría que "encontró su voz" o "encontró su lenguaje". Lo cierto es que se olvidó de escribir correctamente y empezó a producir a la desordenada la mezcla de soliloquios, reflexiones contradictorias, confesiones personales turbadas y turbadoras, opiniones de incontrolada insolencia, alucinaciones, blasfemias, y demás vuelos del espíritu que no venían realmente anunciados en la corrección del estilista del soneto y del entusiasta de Chopin. ${ }^{4}$

Dicho cambio alberga, entre otros elementos, la blasfemia; es decir, "la palabra injuriosa contra Dios, la Virgen o los santos". El blasfemo no ocupa el lugar del hereje, pero la línea divisoria es muy tenue. Nosotros consideramos, a la luz de lo manifestado por Lauer, que el cambio de estilo en Adán obedece a un cambio en su concepción religiosa.

Como hemos mencionado, la Iglesia católica define la herejía como la negación o duda pertinaz de una verdad que debe asumirse con fe. El hereje, quien ha recibido el bautismo, no está fuera de la creencia, sino que se encuentra en una perspectiva de incredulidad. La "herética" de Martín Adán es una condición de posibilidad de su propia obra y alberga tres aspectos en relación a la tradición cristiana: cuestionamiento, alejamiento y confrontación. No se trata propiamente de una "herejía" que se ubica a nivel teológico; sino en el plano poético. En el Catecismo podemos leer la definición de "herejía" y de otros términos vinculados a éste:

\footnotetext{
${ }^{3}$ Alarco, op. cit; p. 119.

${ }^{4}$ Lauer, Mirko, Martín Adán. Retrato del artista, en: El Caballo Rojo. Suplemento de El Diario de Marka, 181 (23 de octubre de 1983), p. 7.
} 
La incredulidad es el menosprecio de la verdad revelada o el rechazo voluntario de prestarle asentimiento. "Se Ilama herejía la negación pertinaz, después de recibido el bautismo, de una verdad que ha de creerse con fe divina y católica, o la duda pertinaz sobre la misma; apostasía es el rechazo total de la fe cristiana; cisma, el rechazo de la sujeción al Sumo Pontífice o de la comunión con los miembros de la Iglesia a él sometidos" (CIC can. 751). ${ }^{5}$

Detengámonos en el concepto de herejía. La negación o duda pertinaz de una verdad cristiana convierten al creyente en un hereje. En otras palabras, se exige al devoto que crea en una verdad, no por efecto de la razón, sino por medio de la fe.

En el Escrito a ciegas observamos las dudas o cuestionamientos del poeta de las verdades reveladas. Desde la perspectiva cristiana la duda es alejamiento. Para Martín Adán también; pero no todo alejamiento lo conduce a la duda. En algunos momentos el poeta alcanza una distancia tal de los dogmas cristianos que le permite afirmar y no dudar de sus hallazgos verbales.

La investigadora argentina Celia Paschero se encontraba en Lima a inicios de los años sesenta buscando material bibliográfico para elaborar su tesis doctoral La poesía peruana contemporánea. Para tal efecto envió una tierna misiva a nuestro poeta. Aquí un fragmento:

Martín Adán: ¿el motivo de esta carta? Además del simplemente afectuoso (que es el más importante) este otro: pedirle a usted datos sobre su propia vida... Deje usted de lado toda su bohemia o cuélguela íntegra en lo que me escriba y, con mucho humor, hábleme de usted, ¿lo hará? ${ }^{6}$

Como mencionamos líneas arriba, Martín Adán nos entregó el Escrito a ciegas. Este poemario, más que una respuesta a Celia Paschero, es la compleja elaboración de una serie de interrogantes vitales del poeta. Con ello se sitúa no sólo en la perspectiva de lo que la investigadora "ignora", sino en la de aquel que otorga un estatuto positivo a la pregunta. Al final del Escrito a ciegas tenemos una sensación de haber hallado muchas respuestas. Sin embargo, la indagación del poeta por su propio ser había comenzado mucho antes. En el Aloysius Acker, escrito hacia 1932, poema perfectamente inacabado y vanamente destruido, podemos encontrar algunos rastros de la búsqueda desesperada del poeta por su identidad, que no dejaremos de apreciar en el resto de su obra. John Kinsella ha hecho notar la preocupación del poeta por ciertas constantes:

\footnotetext{
${ }_{5}^{5}$ Catecismo de la Iglesia católica, Lima: Misión Jubilar Lima-Perú, 1993, pp. 464-465.

${ }^{6}$ Carta de Celia Paschero a Martín Adán, en: Martín Adán, Escrito a ciegas, Lima: Librería-Editorial Juan Mejía Baca, 1961. Dicha carta aparece como presentación al poemario.
} 
Si la mayor parte de su poesía tendió a sacar a la luz los mismos temas y repetir las mismas obsesiones, de la misma manera se pueden detectar ciertos cambios claros relacionados con el tema y la estructura. ${ }^{7}$

Esto nos permite trazar una línea que une toda la obra poética del autor, pero sin desconocer los cambios operados en su escritura y creencia. Es pertinente señalar que en el Escrito a ciegas el cambio en su estructura va de la mano con la distancia que establece el poeta con la tradición cristiana. Por ello, dejamos de lado, por algunos momentos, el término hegeliano de "conciencia desventurada", el cual tiene como supuesto culminante el de la angustia. Aquí, nos interesa su relación con la mencionada tradición en lo que tiene de irónica, de ruptura, de distancia. Aquella "serena sabiduría" que acompaña, según Mirko Lauer, los versos de La mano desasida, puede también sustentar las líneas del Escrito a ciegas.

En cuanto al pedido de la escritora argentina, en ningún momento apreciamos "datos sobre su propia vida" -la del poeta- en el poemario, aunque sí la revelación auténtica de su ser. Observamos su carácter autobiográfico, pero no el de una autobiografía convencional, expresada en términos positivos; es decir, aquellos datos precisos que suelen acompañar a una biografía que se precie de ser tal: año de nacimiento, profesión, estudios, familia, matrimonio, libros publicados, reconocimientos, etc. Se trata de una autobiografía de carácter esencial, que atañe al ser humano en toda su dimensión. El poeta empieza a describir y descubrir un mundo tomando distancia de los presupuestos cristianos; es decir, empieza a dar cuenta de lo más inmediato que puede constatar:

¿Quieres tú saber de mi vida?

Yo sólo sé de mi paso,

de mi peso,

de mi tristeza y de mi zapato. ${ }^{8}$

En los versos que siguen podemos apreciar el término "vocación", que puede ser entendido como la "inclinación a cualquier estado, profesión o carrera", pero también si apelamos a su etimología significa "acción de llamar"; está referido a la "inspiración con que la divinidad llama a algún estado, especialmente al de religión".

\footnotetext{
7 Kinsella, John, Lo trágico y su consuelo. Estudio de la obra de Martín Adán, Lima: Mosca Azul Editores, 1989, p. 181.

${ }^{8}$ Martín Adán, Obra poética, Lima: Edubanco, 1980, p. 145.

${ }^{9}$ Vocación (Del lat. vocatǐo, -ōnis, acción de llamar). 1. f. Inspiración con que Dios llama a algún estado, especialmente al de religión. Real Academia Española, Diccionario de la lengua española, Madrid: Espasa-Calpe, 2004, p. 2313.
} 
vinculación entre el mundo divino y el humano. Por ello es significativo que Adán no nombre explícitamente a Dios en este poemario y sólo lo mencione como el "Creador".

¿Por qué preguntas quién soy,

Adónde voy?... Porque sabes harto

Lo del poeta, el duro

Y sensible volumen de ser mi humano,

Que es un cuerpo y vocación,

Sin embargo. ${ }^{10}$

El verso -"que es un cuerpo y vocación" guarda una íntima relación con el que leeremos más adelante - ¿Soy la Materia o el Milagro?"-. Los términos "cuerpo" y "Materia" son de naturaleza tangible, en tanto los de "vocación" y "Milagro" evocan una "realidad" intangible, si nos permiten la expresión. Según la teología cristiana, en un milagro tenemos dos aspectos definidos. Por un lado, la situación, el hecho mensurable del milagro; es decir, el cuerpo que padece o se beneficia con el milagro y, por otro, el elemento divino que obra en la materia. Las aguas del Mar Rojo -materia del milagrose abren para dejar pasar al pueblo elegido -milagro-. También debemos resaltar que en el primer caso se utiliza la conjunción "y"; es decir, el poeta alberga ambos elementos -cuerpo y vocación-. Sin embargo, en el segundo caso se utiliza la disyunción "o" que enfatiza la separación entre el elemento divino y el terrenal, remarcando con ello la duda del verso anterior: "¿Soy la Creatura o el Creador?"

En los siguientes versos encontramos la primera desavenencia de Martín Adán con la tradición cristiana: en manos del poeta -y no en las del Creadorse encuentra la decisión sobre su muerte. La Iglesia católica condena que el hombre pueda terminar con su existencia por voluntad propia.

El suicidio contradice la inclinación natural del ser humano a conservar y perpetuar su vida. Es gravemente contrario al justo amor de sí mismo. Ofende también al amor del prójimo porque rompe injustamente los lazos de solidaridad con las sociedades familiar, nacional y humana con las cuales estamos obligados. El suicidio es contrario al amor del Dios vivo."

El poeta asume la decisión de terminar con su existencia. La primera parte del verso de Adán -"Si nací"- Ileva consigo una posibilidad contraria de carácter ilógico: pudo no haber nacido. El nacimiento aquí no depende de

\footnotetext{
${ }^{10}$ Martín Adán, op. cit; p. 145.

${ }^{11}$ Catecismo de la Iglesia católica, p. 502.
} 
la existencia del poeta que lo enuncia, sino del año que lo consigna, del registro que lo acredita.

Si nací, lo recuerda el Año

Aquel de quien no me acuerdo,

Porque vivo, porque me mato. ${ }^{12}$

En su relación con los "ángeles" podemos ver otro rasgo que distancia al poeta de la tradición cristiana. En el Catecismo tenemos noticia de ángeles mensajeros y servidores de la divinidad, y custodios o protectores del devoto. Una plegaria en la infancia evocaba su presencia cercana a nuestros pasos y temores.

El ángel de Martín Adán no es el custodio, o el de la guarda que puebla el imaginario del niño; sino el del Hartazgo y Retazo que agobia la vida del poeta. Por un lado, el del deseo saciado y por otro, el del instante efímero. En este último aspecto podemos ver incluso la clave de su propia poética hecha de fragmentos. Acaso como la vida misma, hecha de instantes intensos y discontinuos, no de una realidad lineal y anodina. Podríamos ver aquí una clave para leer la poesía de Martín Adán en esta época; es decir, los textos de esta etapa no sólo optan por el verso libre, sino también por el fragmento. Aquella característica que Mirko Lauer descubre en La mano desasida y que nos parece válida para el Escrito a ciegas:

Salvo algunas tiradas particularmente largas, las secuencias de versos operan como estrofas, y en su mecánica revelan una composición por fragmentos: el "canto a Machu Picchu" es un discurso que recomienza constantemente, y lo hace siempre en un tono épico que inmediatamente se diluye en otros tonos. ${ }^{13}$

No obstante, en el Escrito a ciegas el ángel no es el que guía y cuida al poeta, sino el que lo conduce tropezando por la realidad que aparece como encantadora pero también como turbadora, siempre a la deriva. Inclusive, esta realidad latente se percibe no menos evasiva que aquella que trataba de asir en Travesía.

La soledad en el "Día"; es decir, en el Reino Escatológico, es asumida como un acto individual que no involucra a la especie humana. Aquí su lado divino que no alcanza a cabalidad. El "absoluto" -libre de determinaciones o relaciones- en la "Zoología" coloca el acento en su lado "animal", en donde el pensamiento, como antes la "soledad", lo excluye. Sin embargo, el poeta, con la imagen del "carnívoro feroz", enfatiza la idea de que en

12 lbid; p. 145.

${ }^{13}$ Lauer, Mirko, Los exilios interiores, Lima: Mosca Azul Editores, 1983, pp. 46-47. 
algún momento se produjo o consumó su anhelo; pero que no es capaz de dar cuenta en palabras de este acontecimiento.

Y no alcancé al furor de lo divino

$\mathrm{Ni}$ a la simpatía de lo humano.

Lo soy y no lo siento ni así me siento.

Soy en el Día el Solitario

Y el absoluto en la Zoología si pienso,

O como carnívoro feroz si agarro. ${ }^{14}$

El término "resurrecto" tiene vinculación con el verso "porque vivo, porque me mato". Tanto la "resurrección" como la "muerte" son actos únicos e irrepetibles; salvo cuando una instancia divina permita lo contrario: la resurrección de Lázaro por medio de Jesús. En términos generales, la resurrección ocurrirá al final de los tiempos para toda la humanidad. A Martín Adán sucesivas muertes le permiten sucesivas resurrecciones. Pero estas "resurrecciones" no son procuradas por obra divina; sino por el "coito", que es "ciego y vano", sin visión ni vislumbre de Reino Escatológico alguno.

¡Y con todos mis sueños resoñados,

Y con toda la moneda recogida,

$Y$ con todo mi cuerpo, resurrecto

Tras cada coito, ciego, vano, sin pupila!... ${ }^{15}$

En la tradición cristiana el acto divino de la creación aparece como único e irrepetible. Los seres pueden renovarse generación tras generación, pero ese acto único de creación contiene a todas las creaturas. Como leemos en el Catecismo:

Nuestra profesión de fe comienza por Dios, porque Dios es "el Primero y el Último" (Is 44, 6), el Principio y Fin de todo. El Credo comienza por Dios Padre, porque el Padre es la Primera Persona Divina de la Santísima Trinidad; nuestro símbolo se inicia con la creación del cielo y de la tierra, ya que la creación es el comienzo y el fundamento de todas las obras de Dios. ${ }^{16}$

En los versos siguientes está el núcleo de la "herejía" de Martín Adán. Podemos apreciar dos aspectos del distanciamiento del dogma cristiano por parte del poeta. El primero, la duda. La fe del devoto es inquebrantable,

\footnotetext{
14 Ibid.; p. 148.

${ }^{15}$ Loc. cit.

${ }^{16}$ Catecismo de la Iglesia católica, p. 53.
} 
no admite el cuestionamiento. El segundo, asumir una disyuntiva en donde es posible no ser la "Creatura" sino el "Creador".

¿Soy la Creatura o el Creador?

¿Soy la Materia o el Milagro?

¡Qué mía y qué ajena tu pregunta!...

¿Quién soy? ¿Lo sé yo acaso?

¡Pero no, el Otro no es!

¡Sólo yo en mi terror y en mi orgasmo! ${ }^{17}$

Si tomamos como ejemplo el "milagro" ocurrido en las aguas del Mar Rojo, la "materia" serían las aguas que siguen su cauce y el "milagro", la acción divina que divide las aguas del mar para procurar la liberación del pueblo elegido. Si extendemos esta consideración a la "creación", la humanidad no es sino la "materia del milagro". La pregunta del poeta lo sitúa en una perspectiva en donde él puede ser la instancia divina o creadora que obre sobre una materia, en este caso, las palabras. Martín Adán se sitúa en el umbral. Si mira al pasado, Dios obra en cada una de sus acciones. Si mira al futuro, el poeta se hace responsable por cada uno de sus versos.

Perdida la relación con la divinidad, el poeta experimenta su ser en el "terror o en el orgasmo". Puede llamar la atención que términos como "orgasmo" y "creador" figuren en un mismo fragmento o separados por apenas unos versos. Pero recuérdese que Adán está escribiendo desde una nueva perspectiva frente a la divinidad, justamente la que lo distancia.

Es pertinente señalar que en el Escrito a ciegas el cambio de estilo coloquial y no barroco como en Travesía- va de la mano con la distancia que establece el poeta con la tradición cristiana. Por ello, dejamos de lado, por algunos momentos, el término hegeliano de "conciencia desventurada", el cual tiene como supuesto culminante el de la angustia. Aquí, nos interesa su relación con la mencionada tradición en lo que tiene de irónica, de ruptura, de distancia. Aquella "serena sabiduría" que acompaña, según Mirko Lauer, los versos de La mano desasida, puede también sustentar las líneas del Escrito a ciegas.

Borges sostenía que si el pecado cometido en el Paraíso condenaba a toda la Humanidad, no era extraño que la muerte de un judío en la cruz la redimiera. Así tenemos que pecado y salvación viajan a través de los siglos por la sangre de los creyentes. Cristo no viene a salvar a los justos, sino a los pecadores, razón por la cual nadie puede sentirse condenado

17 LoC. cit. 
de antemano. Inclusive, la salvación no se produce, en rigor, por obra del creyente sino por la misión del Salvador:

Tal es el sentido de la siguiente afirmación de la Iglesia (cf Cc. de Trento: DS 1608): los sacramentos obran ex opere operato (según las palabras mismas del Concilio: "por el hecho mismo de que la acción es realizada), es decir, en virtud de la obra salvífica de Cristo, realizada de una vez por todas. De ahí se sigue que "el sacramento no actúa en virtud de la justicia del hombre que lo da o recibe, sino por el poder de Dios" (S. Tomás de A., s. th. 3, 68, 8). ${ }^{18}$

En los versos que siguen, Martín Adán no asume la propia posibilidad de salvarse. La búsqueda ontológica de un nuevo "ser" lo ha llevado a vislumbrar que dicha salvación podría obrar si él fuera "otro". Ni la "sensibilidad" ni el "entendimiento" lo han llevado a buen puerto. Cuando experimenta el éxtasis visionario no puede dar cuenta de éste sin desnaturalizarlo.

Yo buscaba otro ser

Y ése ha sido mi buscarme.

Yo no quería ni quiero ya ser yo,

Sino otro que se salvara o que se salve

No el del Instinto, que se pierde,

$\mathrm{Ni}$ el de Entendimiento, que se retrae. ${ }^{19}$

En el Aloysius Acker (1932) el poeta se ha referido a un "otro" que "odia" y que no tiene "hermano". En la atmósfera del poema no es difícil apreciar que el "otro" es la propia divinidad. Aquí en el Escrito a ciegas (1961) el "otro", lo más lejano, es también una proximidad que se desvanece. El "aire" puede parecer un obstáculo para el ave que ha desplegado sus alas, pero no lo es. Necesita de ese elemento para volar. El poeta necesita de ese otro fantasmal para desplegar su verso. La sorpresa del reencontrarse es similar al padecimiento de los sueños resoñados: siempre las mismas obsesiones; siempre el mismo padecimiento cuando volvemos la mirada. El "cielo", más que última morada, aparece como una realidad dispuesta a terminar con los días del poeta.

El Otro, el Prójimo, es un fantasma

¿Existe el aire,

Donde te asfixias y recreas

\footnotetext{
${ }^{18}$ Catecismo de la Iglesia católica, pp. 264-265.

19 Ibid., 147.
} 
Respirando, tu cuerpo inane?

¡No, nada es sino la sorpresa

Eterna de tu mismo reencontrarte

Siempre tú los mismos entre los mismos muros

De las distancias y de las calles!

¡Y de los cielos estos techos

Que nunca me ultiman porque nunca caen!20

Platón, en el Fedro, nos habla del origen divino del amor y de la locura. Ésta se evidencia en la mántica, la profecía y la poesía. Sobre la poesía nos dice:

Pero hay un tercer estado de posesión y de locura procedente de las Musas que, al apoderarse de una alma tierna y virginal, la despierta y la llena de un báquico trasporte tanto en los cantos como en los restantes géneros poéticos, y que, celebrando los mil hechos de los antiguos, educa a la posteridad. Pues aquél que sin locura de las Musas llegue a las puertas de la poesía convencido de que por los recursos del arte habrá de ser un poeta eminente, será uno imperfecto, y su creación poética, la de un hombre cuerdo, quedará oscurecida por la de los enloquecidos. ${ }^{21}$

Por ello Marsilio Ficino, traductor y comentarista de la obra platónica, da cuenta de los "furores divinos" en los siguientes términos: "Al haber cuatro especies de furor divino -según le parece bien a nuestro Platón-: amor, adivinación, misterio y poesía, también el amor se atribuye a Venus, la adivinación a Apolo, el misterio a Dionisos y la poesía a las Musas". ${ }^{22}$ Martín Adán considera que no ha logrado tal "posesión y locura" en su obra. Tampoco la "simpatía" -en griego, "comunidad de sentimientos"- o afinidad con sus semejantes.

En los versos que siguen, Martín Adán establece una relación intensa entre el "Amor" y la "Creación". No se trata de un "Amor" que se vincula con otro ser para dar lugar a una nueva vida, sino de un "Amor" que se alimenta de su propia esencia para que se renueve la "Creación" -las creaturas-. ¿Es el amor de dios o el de los hombres el que renueva la "Creación"? El poeta puede "crear" algunas veces, pero desde esa única "Vez":

El Amor no sabía

sino tragarse su substancia

\footnotetext{
20 lbid., p. 147-148.

${ }^{21}$ Platón, Fedro, en: Diálogos, Madrid: Gredos, 1992, 244E-245B.

22 Ficino, Marsilio, Sobre el furor divino y otros textos, Barcelona: Antropos, 1993, p. 5.
} 
y así la Creación se renovaba.

Todo me era de ayer, pero yo vivo;

y a veces creo, y la Vez me amamanta. ${ }^{23}$

En el pensamiento griego el concepto de "Creación" está vinculado al de "Amor". En el Banquete de Platón el "Amor" aparece como el dios más antiguo. Para demostrar tal situación el filósofo se vale de lo manifestado por Hesíodo, Acusilao y Parménides. Los dos primeros sostienen que en el principio existía el "Caos" del que nacieron la "Tierra" y el "Amor". El último enfatiza el principio generativo del "Amor". ${ }^{24}$

El "día" aquel que empieza tras la muerte. En Diario de poeta (1973) leemos: "Cómo andará el humano sin su vino". Los primeros pasos serán tan desconcertantes como aquellos que se dan en una ciudad que es ajena a nuestra verdadera naturaleza. Todo le es ajeno al poeta ya sea como "animal" ya sea como "hombre".

Mi día es otro día,

algún no sé dónde estarme,

a dónde no sé ir en mi selva

entre mis reptiles y mis árboles,

libros y cementos

y estrellas de neón.

Mujeres que se me juntan como la pared y como nadie...o como

madre,

y el recién nacido que sobre mí llora,

y por la calle

todas las ruedas

reales y originales.

Así es mi día cabal,

hasta la última tarde. ${ }^{25}$

Si en algún momento la "piedra" simbolizó, en La mano desasida. Canto a Machu Picchu (1961), los anhelos de Martín Adán poeta por alcanzar lo

\footnotetext{
23 lbid., p. 149.

${ }^{24}$ Platón, Banquete, en: Diálogos, Madrid: Gredos, 177E-178B.

25 Ibid., p. 147.
} 
inefable, ahora no es más que un mineral que desconoce precisamente los anhelos del poeta por alcanzar ese mundo esquivo que lo espera a cada momento. Ese mundo esquivo, el Reino Escatológico, el Día, lo sitúa en la perspectiva de la espera. Aquí no hay herejía, sino devoción plena.

Todo lo ignoras porque eres de piedra,

Todo lo ignoras porque es otro el día;

Todo lo ignoras porque es otro el río

Y sigue siendo así mi todavía. ${ }^{26}$

La soledad espera al poeta en cada pared de la ciudad, "cómplice, disimulándose". También lo espera la muerte o la última tarde, descrita en estos versos como una "bestia fea", que por ahora duerme, pero que desplegará toda su furia cuando despierte. El poeta no quiere valerse de ningún intermediario - ni de la "rosa" ni de la "piedra"- para subir al cielo. Esta situación le revela precisamente su naturaleza mortal. Sin embargo, ese "Día" que lo despojará de sus temores, es visto con recelo, como si a partir de él empezara otra vida con no menos incertidumbres.

¡Allá en el Rincón,

La furia dormía!

Era una bestia fea, una bestia cualquiera,

Con su colmillo y con su malicia.

Yo no quiero subir por tu piedra.

Temo. ¡Temo, Mi Día!

¡Temo, Mi Ser El Vivo y El Eterno,

Temo, Mi Propia Maravilla!...27

En el segundo capítulo del presente estudio nos hemos referido a la agonía de Martín Adán. Ésta puede ser entendida como el estado de congoja que antecede a la muerte; pero también, como lo recuerda Unamuno, como lucha. En la obra de Adán podemos encontrar ambas acepciones. "La edad de la agonía", en los versos que siguen, se encuentra más cerca del sentido etimológico mencionado por el autor de La agonía del cristianismo. Es cierto que todo momento antecede a la muerte, pero en el caso del poeta se trata de un estado al que no siempre se accede. Sin embargo, una vez que se ha llegado a él, la persona puede ir descubriendo lo esencial de la vida,

${ }_{26}$ lbid., p. 161.

27 Ibid., p. 317. 
por lo que se hace innecesario que el poeta se lo confíe. Con el término "Amiga" se refiere tanto a Celia Paschero como a cualquier interlocutor que desee seguir el itinerario del poeta. Unos versos más adelante la "Amiga" no será otra que la misma poesía.

¡Cuando no seas más que ser,

si llegas a la edad de la agonía!...

¡Cuando sepas, verdaderamente,

que es ayuntamiento de muerte y vida!...

¡Entonces te diré quién soy,

seguro sí, que ya sin voz, Amiga!28

El verso "que se curan con hierbas eficaces" contrasta con el de "el mundo real y la ciencia humana", distancia que se acrecienta con los que siguen a cada cual, "los puros animales que te hablan, allá entre piedras inmateriales" "y "donde con una pelota los muchachos aparentes, hediondos gozaban". El poeta nos sitúa entre dos mundos que se desenvuelven con criterios distintos. En el primero nos acerca a una perspectiva tradicional y el segundo a una moderna. ¿Campo y ciudad? ¿La ciudadela de Machu Picchu y la Estación de Desamparados?

La vida ha sido descrita en el Escrito a ciegas a la vez como "engaño y encanto". En los siguientes versos observamos que se la describe como un "delirio", con lo que se afianza la idea anterior. La tarea del poeta consiste en dar cuenta de esa "sombra deslumbrante" llamada vida. En este momento Adán acepta que no ha encontrado en esta vida su realización, ya sea en términos celestiales, excelsos o en términos volcánicos, mundanos, humanos. Asimismo, el poeta marca una diferencia entre el "Tiempo" -con mayúscula inicial- inmemorial, absoluto, si nos permiten expresarlo así, y un "tiempo" -con minúscula inicial- mundano, relativo, en donde el hombre realiza sus acciones y aspiraciones. Martín Adán nos dice que el "Tiempo" inmemorial tarda en llegar a su punto de "olvido o de sensibilidad" -su presencia lacera al poeta-, devorando así las ansias de Adán de acceder al imaginario que anuncia con furia estruendosa:

que se curan con hierbas eficaces

los puros animales que te hablan

allá, entre piedras inmateriales

el mundo real y la ciencia humana,

${ }^{28}$ Ibid., p. 148. 
donde, con una pelota

los muchachos aparentes, hediondos gozaban.

Sí, la vida es un delirio así, y sin embargo,

en esa vida no estuvo mi nada,

ninguna, pero real, pero celeste o volcánica.

¡Qué tarde llega el Tiempo

a su punto de olvido o de sensibilidad!

Viene arrastrando, como el aluvión,

de cúmulo, de suelo, de humanidad..$^{29}$

Si en los versos anteriores el "Tiempo" tardaba en llegar al poeta, ahora éste es el que llega a destiempo a sí mismo. Sólo en el "instante eterno" del hallazgo en la poesía o en la vida misma el autor alcanza su identidad. Ni la "rosa", la "piedra" o el "hermano" son reclamados en esta instancia. No obstante, dicha identidad no está exenta de sufrimiento. Los versos finales guardan relación con el concepto de agonía en su significación etimológica de lucha.

¡Cuán a destiempo llega uno a sí mismo!

¡Cuán inesperado y desesperado cualquier ya,

todo yo que cae con el Tiempo

desde nunca siempre y para siempre jamás!

¡Qué madrugada eterna no dormida

lo de resolverme en el hacer $y$ en el pensar! ${ }^{30}$

Solo ante Dios, solo ante el mundo. El poeta tanto en su búsqueda de lo inefable como en su tránsito por el mundo se encuentra en estricta soledad. Aquí la creación está vinculada a la tarea poética y a la formación personal. Ambas albergan la dificultad de una concreción cabal, ya sea en términos poéticos o vitales.

La Soledad es una roca dura

contra la que arroja el Aire.

Está en cada pared de la Ciudad, cómplice, disimulándose.

\footnotetext{
${ }_{29}$ lbid., pp. 148-149.

30 Ibid., p. 149.
} 
Me arrojó o me arrojo, sin cesar

yo soy mi impedimento y mi crearme. ${ }^{31}$

La vida ha sido descrita en términos de asombro, engaño y delirio. En los versos que siguen el poeta duda de todo esto y vislumbra la posibilidad de que sea otra cosa sobre la que hay que indagar o adivinar, pero de la que nunca se tendrá una respuesta concreta. Asimismo, Adán nos dice que en algún momento tuvo la eternidad deseada y la desechó. Por ello, pide un poco de "tiempo" al "Tiempo" para poder recuperarla.

Si mi vida no es esto

¿qué será la vida?... ¿Adivinanza?...

Que me dé tiempo el Tiempo, a más del suyo,

y yo me reharé mi eternidad;

lo que me falta,

porque la eché...me estuvo un momento demás. ${ }^{32}$

Un tono sereno -que es abandonado en pocas instancias del poemaacompaña al Escrito a ciegas. ¿Qué significa "saberlo todo"? No se trata aquí de una acumulación sistemática de conocimientos adquiridos a lo largo de una vida, sino que está referido a aquella conclusión al final de la vida, de que todo ha sido ilusión, deslumbramiento que no produce maravillarse sino ceguera. Y más que el poeta diga su vida, le pide al interlocutor un tránsito por el propio camino requerido, sólo así podrá encontrar las respuestas en su propio corazón.

Se cierra el círculo del Escrito a ciegas. La sabiduría consiste en aceptar que no hay grandes preguntas, por lo tanto, desvirtúa la ingenuidad de indagar por grandes respuestas. “¿Quieres tú saber de mi vida?” preguntaba al inicio el poemario. Ahora, al final del mismo, nos encontramos en idéntica posición con respecto a la indagación inicial. Las respuestas del poeta no pasan por una serie de indicaciones dichas a su interlocutor para que éste transite por la vida con prudencia; sino por sugerir que las respuestas por las que indaga se encuentran en él mismo. Para descubrirlas es menester seguir el propio camino tal como lo ha seguido el poeta: el encuentro del instante.

Tú no sabes nada;

tú no sabes sino preguntar,

tú no sabes sino sabiduría

\footnotetext{
${ }^{31}$ LoC. cit.

32 Ibid, p. 150.
} 
pero sabiduría no es estar

sin noción de nada, sino proseguir o seguir

a pie hacia el ya. ${ }^{33}$

\section{REFERENCIAS BIBLIOGRÁFICAS}

ALARCO, Luis Felipe, Tres autores, Lima: Empresa Editora Amauta, 1995.

CATECISMO DE LA IGLESIA CATÓLICA, Lima: Misión Jubilar Lima-Perú, 1993.

FICINO, Marsilio, Sobre el furor divino y otros textos, Barcelona: Anthropos, 1993. Edición bilingüe. Selección de textos, introducción y notas de Pedro Azara. Traducción de Juan Maluquer y Jaime Sainz.

KINSELLA, John, Lo trágico y su consuelo. Estudio de la obra de Martín Adán, Lima: Mosca Azul Editores, 1989.

LAUER, Mirko, Los exilios interiores, Lima: Mosca Azul Editores, 1983.

"Martín Adán. Retrato de una artista", en: El Caballo Rojo. Suplemento de El Diario de Marka, 181 (23 de octubre de 1983), p. 7.

MARTíN ADÁN, Escrito a ciegas, Lima: Librería-Editorial Juan Mejía Baca, 1961.

La casa de cartón, Lima: Peisa, 1974. Prólogo de Luis Alberto Sánchez y colofón de José Carlos Mariátegui.

, Obra poética, Lima: Edubanco, 1980. Edición, prólogo y notas de Ricardo Silva-Santisteban.

PLATÓN, Banquete, en: Diálogos, Madrid: Gredos, 1992.

---------, Fedro, en: Diálogos, Madrid: Gredos, 1992.

Real Academia Española, Diccionario de la lengua española, Madrid: Espasa-Calpe, 2004.

\footnotetext{
33 lbid, p. 151.
} 
Máximo Andrés Piñeiro Mayorga (Lima). Es licenciado en filosofía por la Universidad Nacional Mayor de San Marcos (2002). En la misma universidad concluyó sus estudios de maestría en Historia de la Filosofía (2004). Ha publicado dos libros. El primero, un poemario, Diotima de Mantinea (Dedo Crítico Editores, 1997) y, el segundo, Desventura en Extramares. Conciencia desgarrada en la poética de Martín Adán (Lima, Fondo Editorial de la UNMSM, 2003), tesis con la que obtuvo su licenciatura. Entre sus artículos, aparecidos en diversos diarios y revistas de la capital, destacan: La invención de Casares (Lima, La República, 1998); Los Ilantos de Montalbetti (Lima, Hueso Húmero, 2003) y La controversia de Valladolid: Cinco siglos después (Lima, Instituto de Ciencias y Humanidades, 2005). Actualmente, se encuentra realizando un estudio sobre la influencia de la mística judía en el pensamiento del filósofo alemán Walter Benjamin.

apineiro960@hotmail.com

Recepción: 20 de noviembre 2008. Aprobación: 20 de enero de 2009. 